\title{
Concepção de produtos para a utilização de resíduos madeireiros de espécies arbóreas da Amazônia
}

\author{
Conception of products for the use of wood residues of Amazonian tree species
}

SILVA, Geislayne Mendonça; Designer; Universidade Federal do Amazonas

geislayne94@gmail.com

NASCIMENTO, Claudete Catanhede do; Drá; Instituto Nacional de Pesquisas da Amazônia

catanhed@inpa.gov.br

SILVA, Jean Machado Maciel; MSc; Universidade Federal do Amazonas

jeansilva@ufam.edu.br

\section{Resumo}

A utilização de resíduos madeireiros é muito incentivada por instituições de pesquisa, órgãos e universidades. Um dos principais polos florestais do Brasil está concentrado na região norte de onde todo esse potencial provém de florestas nativas, apesar do incentivo, ainda existem muitas objeções quanto ao beneficiamento da madeira por questões burocráticas, ambientais e logísticas no campo da exploração madeireira. A pesquisa em questão visou classificar resíduos provenientes de processamento mecânico de madeiras certificadas e resíduos florestais para produção de produtos com valor agregado e sustentabilidade. Para seu desenvolvimento foi realizado levantamento dos dois tipos de resíduos disponíveis nas serrarias e em áreas de floresta, registrando suas características como comprimento e largura, cor da madeira, se estavam atacadas por fungos ou coleópteros. Os produtos confeccionados mostraram a potencialidade do uso dos dois tipos de resíduos na confecção de moveis sem perder as características das madeiras de forma sustentável.

Palavras Chave: Resíduos Madeireiros; Sustentabilidade; Ecodesign.

\begin{abstract}
One of the main forest poles in Brazil is concentrated in the northern region where all this potential comes from native forests, despite the incentive, there are still many objections regarding wood processing due to bureaucratic, environmental and logistic issues in the field of logging. The research in question aimed to classify residues from mechanical processing of certified timber and forest residues for the production of products with added value and sustainability. For its development, a survey of the two types of residues available in sawmills and in forest areas was carried out, recording their characteristics as length and width, color of the wood, if they were attacked by fungi or beetles. The products made showed the potential of the use of both types of waste in the manufacture of furniture without losing the characteristics of the wood in a sustainable way.
\end{abstract}

Keywords: Waste wood; Sustainability, Ecodesign. 


\section{Introdução}

A utilização de resíduos madeireiros provenientes de processamento mecânico e de arvores naturalmente caídas é muito incentivado por instituições de pesquisa, órgãos e universidades. Uma vez que a partir do desdobro e do beneficiamento primário e secundário da madeira é gerada uma grande quantidade de resíduos onde os mesmos são utilizados para a geração de energia. São materiais combustíveis e degradáveis, classificados conforme a NBR 10004 - "Resíduos Sólidos Classificação" da ABNT como resíduos sólidos de Classe II - Não Inertes. Em condições naturais não há riscos à saúde pública, pois não são tóxicos nem patogênicos (LOPES, 2009).

Além do beneficiamento da madeira existe outro fator que colabora para a geração de resíduos como a classificação da madeira para fins comerciais. Quanto a isso Dias (2011) afirma que parte desses resíduos pode ser originada de defeitos como trincas, presença de oco na tora, deterioração por fungos e insetos que podem ocorrer na madeira maciça. Lopes (2009, p. 03) afirma que esses resíduos, não são utilizados pela indústria de processamento primário (desdobro) e secundário (beneficiamento) da madeira por causa de limitações tecnológicas ou restrições de mercado. Afirma também, que a falta de informação e as dificuldades intrínsecas ao aproveitamento do resíduo madeireiro levam ao abandono de parte dele na área da colheita, para ser queimado a céu aberto ou descartado em cursos d'água, no caso do processamento primário.

Um dos principais polos florestais do Brasil está concentrado na região norte de onde todo esse potencial provém de florestas nativas, mesmo assim ainda existem muitas objeções quanto ao beneficiamento da madeira por questões ambientais e logísticas no campo da exploração madeireira. A má utilização desse recurso resulta em altos índices de desperdícios. Entretanto, os resíduos de forma geral, tanto de origem madeireira como de outros tipos, vêm ganhando notoriedade ao passo que empresas e a própria sociedade em si vem criando meios que permitam a utilização de resíduos visando a sustentabilidade e preservação de recursos naturais ou seu uso planejado. Silva (2017) afirmou que tem ocorrido aproveitamento crescente da madeira, devido às pressões exercidas pela sociedade na criação de leis ambientais mais rigorosas, as necessidades econômicas, as exigências do mercado e ao desenvolvimento tecnológico. Lopes (2009, p. 06) afirma que:

Sempre que econômica e tecnicamente viável, a valorização de um resíduo é uma alternativa superior ao seu descarte, pois, além de contribuir para a solução de um problema ambiental, pode ajudar a reduzir os custos de produção e os de disposição final dos resíduos não valorizados. Essa valorização, quando bem administrada, faz que o material residual de uma empresa torne-se matéria-prima em outra.

Diante de tal afirmação foi feito um levantamento dos tipos de resíduos madeireiros provenientes de processamento mecânico e de arvores naturalmente caídas disponíveis e foram selecionados dois para o desenvolvimento dessa pesquisa. Sendo estes, peças de madeira atacadas por fungos ou coleópteros e discos de madeira. Uma das propostas de utilização desses resíduos é a concepção de novos produtos, necessitando que os mesmos possam ser produzidos em larga escala, pois a maioria dos artefatos provenientes de resíduos madeireiros são confeccionados artesanalmente, o que acarreta em produtos em que na maioria dos casos não apresentam detalhamento técnico impossibilitando a fabricação em série dos mesmos. Outro fator que impossibilita essa produção em larga escala é a forma do produto, que em sua maioria apresenta uma concepção orgânica dificilmente reproduzível de forma idêntica.

É necessário que se tenha uma visão holística do projeto de produto, onde há um 
planejamento desde os primeiros desenhos esquemáticos contemplando a aquisição da matéria prima, processo de fabricação e ferramentas disponíveis, até o momento de contat0o com o cliente final e se possível, estender essa visão até o fim da vida útil do produto. Venzke (2002, p. 03) define que:

O principal objetivo do Ecodesign é a criação de produtos ecoeficientes, sem comprometer seus custos, qualidade e restrições de tempo para a fabricação. O conceito de ecoeficiencia nos remete a práticas ambientalmente responsáveis, que devem ser concordantes com as políticas e estratégias da empresa. Desta maneira, para que sejam alcançados os objetivos da empresa, com relação aos compromissos ambientais assumidos, é necessário que sejam adotadas algumas práticas durante o projeto de um produto.

Diante da necessidade da reutilização de resíduos madeireiros a partir da concepção de artefatos, esta pesquisa teve como objetivo classificar resíduos provenientes de processamento mecânico de madeiras certificadas e resíduos florestais para produção de produtos com valor agregado e sustentabilidade, propondo soluções com formas fáceis de serem reproduzidas, voltadas a simplicidade sem comprometer o apelo estético. Soluções essas que permitissem a fácil desmontagem de produtos para o transporte, já contemplando a questão de menor espaço ocupado com embalagens de transporte e peso contribuindo de forma significativa com a redução de gastos quanto a logística. A pesquisa sugere que este tipo de resíduo seja visto de forma diferente, mostrando a viabilidade comercial a partir da concepção de produtos que agreguem valor ao mesmo, produtos estes contemplando apelo visual, formal e ergonômico, além da disponibilidade de detalhamento técnico e processo de execução capazes de serem entendidos por terceiros tornando possível a produção em larga escala.

\section{Metodologia}

Toda a pesquisa foi desenvolvida com base na metodologia de desenvolvimento de produto proposta por Barbosa Filho (2009) (FIGURA 01). Primeiramente foi feito um levantamento quanto aos tipos de resíduos madeireiros disponíveis e os artefatos mais comuns com viabilidade comercial.

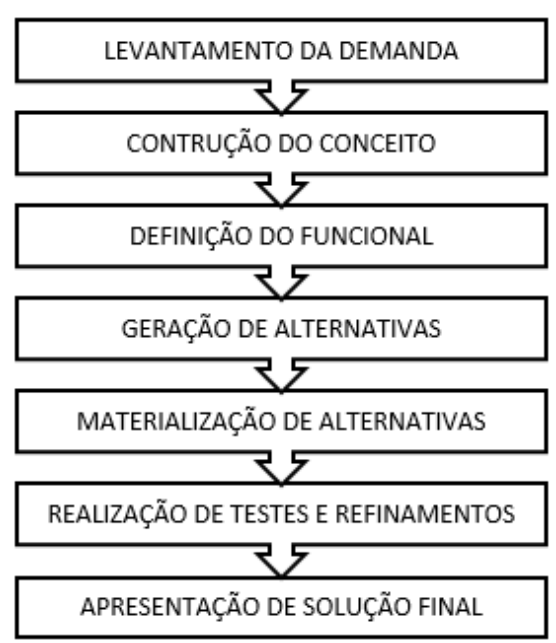

Figura 1. Hierarquização das etapas metodológicas para desenvolvimento de produto. Fonte Própria, 2018.

Após a identificação dos resíduos (FIGURA 02) iniciou-se a etapa de construção do conceito baseado nas características físicas do material (FIGURA 03), onde também foi feita a definição funcional uma vez que os artefatos precisavam ser inseridos em linha de produção e não produzidos de forma totalmente artesanal. 


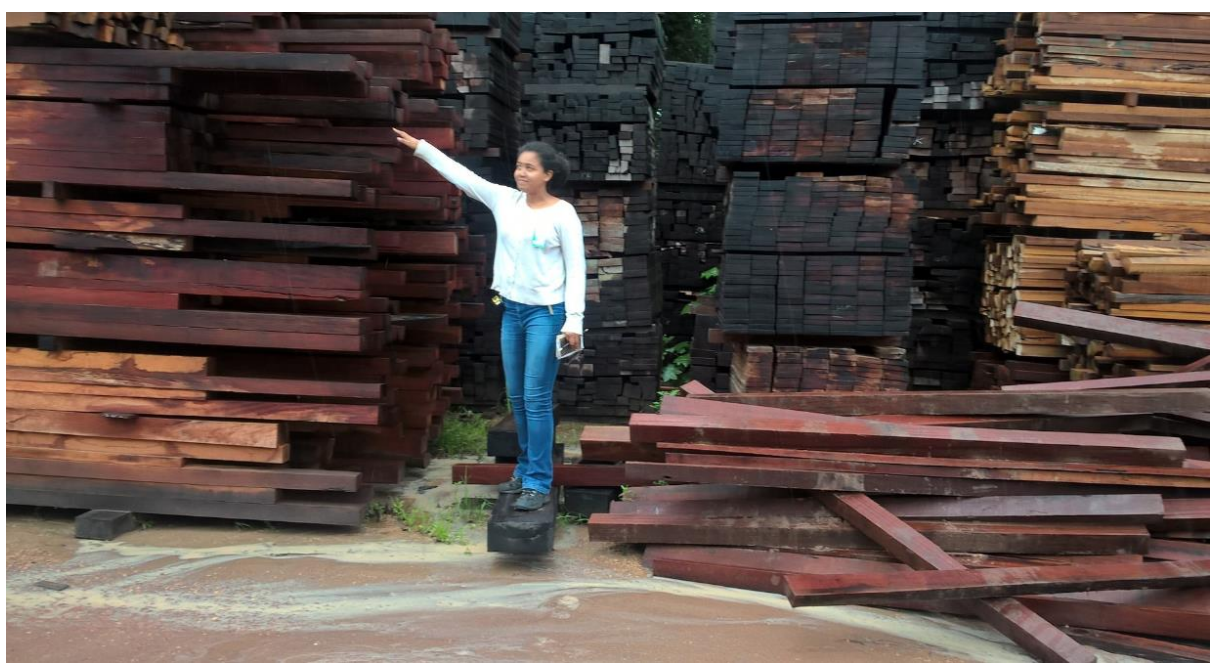

Figura 2. Identificação dos Resíduos. Fonte Própria, 2018.

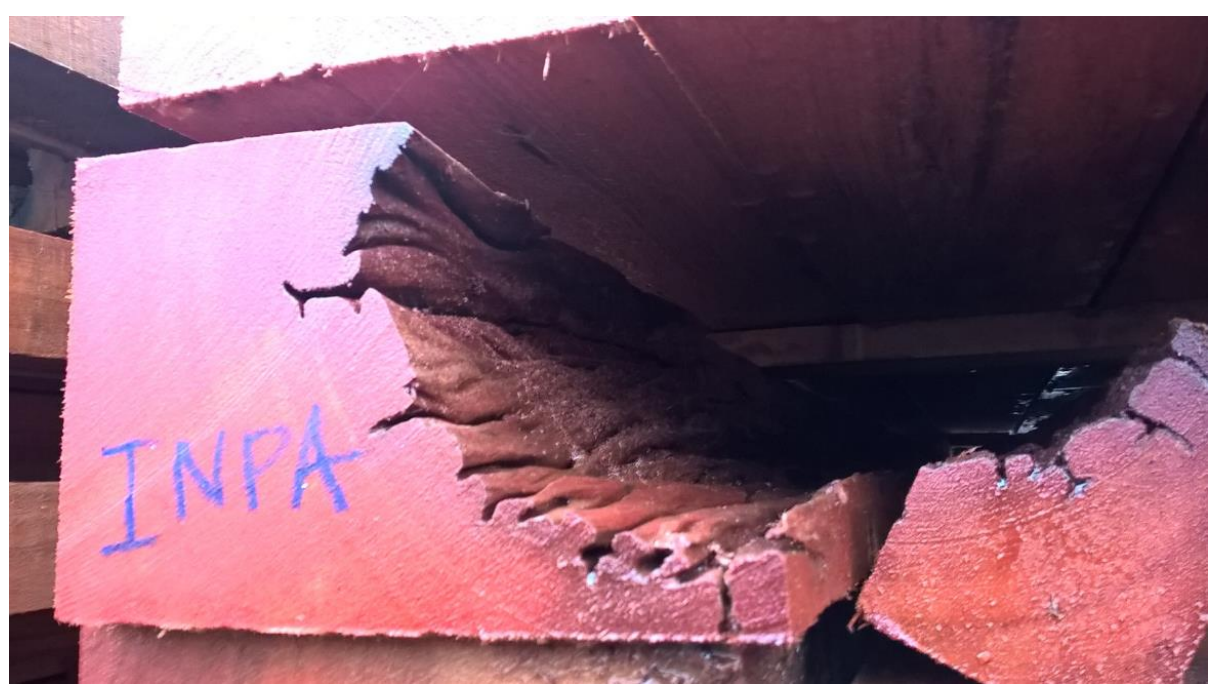

Figura 3. Características físicas dos resíduos. Fonte Própria, 2018.

Após a seleção dos resíduos, os mesmos foram cubados e classificados quanto ao nível de aproveitamento e grau de alteração nas características físicas baseadas no padrão comercializado. Uma vez que o intuito da pesquisa foi mostrar a viabilidade de produção de artefatos a partir de material não introduzido para comercialização, para direcionar o processo de geração de alternativas, foi feita uma relação de requisitos e parâmetros conforme tabela 01. Após esta etapa iniciou-se o processo de geração de alternativas, materialização, realização de testes e refinamento das mesmas. 
Tabela 1 - Relação de requisitos e parâmetros

\begin{tabular}{|c|c|}
\hline Requisitos & Parâmetros \\
\hline \multicolumn{2}{|c|}{ USO } \\
\hline Ergonomia & $\begin{array}{l}\text { Ótima adequação entre o produto design e o } \\
\text { usuário quanto aos limites do mesmo. }\end{array}$ \\
\hline Uso simples e intuitivo & $\begin{array}{l}\text { O produto deve ser facilmente compreendido, } \\
\text { sem depender de conhecimentos } \\
\text { especializados. }\end{array}$ \\
\hline Antropometria & $\begin{array}{l}\text { Adequada relação dimensional entre produto e } \\
\text { usuário }\end{array}$ \\
\hline \multicolumn{2}{|c|}{ FORMA } \\
\hline Praticidade & $\begin{array}{l}\text { Formas mais geométricas aplicando a } \\
\text { modularidade. }\end{array}$ \\
\hline Estilo & $\begin{array}{l}\text { Gerar alternativas com certo apelo estético } \\
\text { procurando valorizar ainda mais o produto. Ex: } \\
\text { Utilizar a técnica da Marchetaria. }\end{array}$ \\
\hline Redução do gasto energético & $\begin{array}{l}\text { As alternativas devem evitar } \\
\text { superdimensionamentos desnecessários, que } \\
\text { levem a maiores gastos energéticos. }\end{array}$ \\
\hline Facilidade durante o processo produtivo & $\begin{array}{l}\text { Utilizar o mínimo de mão de obra e } \\
\text { ferramentas possíveis. }\end{array}$ \\
\hline
\end{tabular}

Fonte: Própria (2018)

\subsection{Geração de alternativa}

Geralmente as alternativas são desenvolvidas para posteriormente selecionar o material para prototipagem da mesma. No caso dessa pesquisa, o caminho foi inverso: primeiramente foram analisados os resíduos disponíveis e depois foi gerada alternativas de utilização dos mesmos, empregando o conceito de ser modular e passível de ser reproduzido por terceiros, mas ao mesmo tempo empregando singularidade em cada artefato.

Sendo os discos de madeira e peças apresentando variações em sua estrutura física causadas por conta do ataque de coleópteros ou fungos, o desafio aqui encontrado foi o de gerar soluções passíveis de serem reproduzidas em escala industrial ao mesmo tempo em que levam consigo as características que atualmente tornam esse material não utilizado pela indústria na produção de artefatos mas sim na incineração dos mesmos para produção de energia.

Para as peças que apresentam apenas variação em sua estrutura fisica foi selecionado o artefato aparador para geração de alternativa e para os discos de madeira foi selecionada mesa de centro.

\subsubsection{Aparador Rio}

Os dois resíduos principais utilizados para a geração dessa alternativa foi uma peça atacada por coleópteros e a outra por fungo manchador, sendo respectivamente, peças de Angelim Vermelho (Dinizia excelsa Ducke) (FIGURA 04) e Marupá (Simarouba amara). O aparador foi selecionado como artefato por ser um móvel que pode ser usado em ambientes como sala de estar ou jantar e também por conta de seu dimensionamento compatível com o resíduo em questão. 


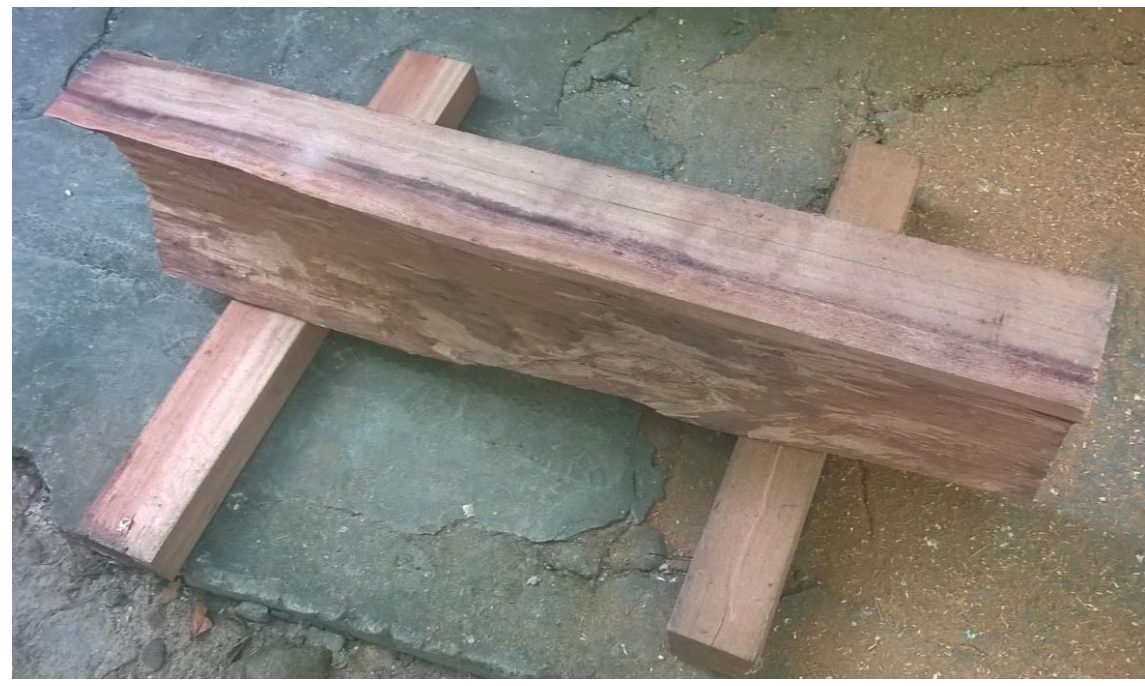

Figura 3. Peça de Angelim Vermelho. Fonte Própria, 2018.

A alternativa proposta foi desenvolvida a partir da visualização das peças e criação de conceito, por meio de desenhos esquemáticos. Após o dimensionamento ser estabelecido a mesma foi modelada em software 3D Solid Edge buscando a visualização tridimensional do artefato, os impasses quanto a ligações das peças, simulações virtuais de uso e interação com o ambiente e mais a geração de detalhamento técnico para protótipo físico. O aparador proposto é de 1,10 $\mathrm{m}$ de comprimento por $28 \mathrm{~cm}$ de largura e $80 \mathrm{~cm}$ de altura, mais contemplou a possibilidade de variação desse dimensionamento fazendo-se necessário obedecer a uma regra simples descrita no processo de fabricação das peças de sustentação (pernas). O detalhe encontrado na junção entre as pernas e as demais peças de ligação também pode ser modificado como detalhado a seguir. Este produto foi constituído de quatorze peças que apresentam apenas formas geométricas podendo ser redimensionadas. Segue a ordem de execução de cada uma:

a) PERNAS: Ao todo são quatro peças que podem sofrer variações em sua altura e largura obedecendo a esta regra: a base foi de $3 \mathrm{~cm}$ de largura e a partir dela um dos lados foi submetido a inclinação de $85^{\circ}$, mediu-se a altura desejada e traçou-se uma reta perpendicular ao lado que tem $90^{\circ}$ em relação a base até atingir a reta inclinada $85^{\circ} \mathrm{em}$ relação a base. Feito isto, traçou-se uma reta paralela à de $90^{\circ}$ a $3 \mathrm{~cm}$ de distância da mesma. Nesta reta marcou-se 7,5 cm a partir da base maior (topo), traçou-se uma perpendicular até atingir a reta inclinada $85^{\circ}$ formando assim um trapézio retângulo. Este trapézio é eliminado da peça com o uso de máquina como serra fita após transferir o desenho para a madeira selecionada para a fabricação das pernas. Depois de realizar os cortes necessários a peça passou por máquinas como plaina desengrossadeira e calibradora além de lixadeira circular. Para acabamento dessas peças utilizou-se lixas de várias granulações e material para acabamento dependendo do tipo de madeira selecionado.

b) APOIO PARA O VIDRO LATERAIS: São duas peças de $24 \mathrm{~cm}$ de comprimento por $6 \mathrm{~cm}$ de altura, com $2 \mathrm{~cm}$ de espessura. Selecionou-se a madeira que a ser utilizada na confecção das peças e em seguida, dependendo da condição dessa madeira, sujeitou-se a mesma a máquinas como serra circular conforme necessidade, plaina desempenadeira e plaina desengrossadeira, após este processo transferiu-se o desenho para a madeira e então a serra de fita foi utilizada para realizar os cortes necessários, então as peças passaram por uma 
máquina chamada calibradora e lixadeira circular.

c) APOIO PARA O VIDRO FRENTE E VERSO: Trata-se de duas peças com $104 \mathrm{~cm}$ de comprimento por $5 \mathrm{~cm}$ de altura e $2 \mathrm{~cm}$ de espessura. Estas duas peças passam pelo mesmo processo descrito para as peças de APOIO PARA O VIDRO LATERAIS.

d) PEÇAS DE LIGAÇÃO FRENTE E VERSO: Duas peças no total com um metro e quatro centímetros de comprimento, por três centímetros de altura e dois centímetros de espessura. Fez-se seleção dos resíduos para posteriormente serem processados em máquinas como serra circular, plaina desempenadeira, plaina desengrossadeira, calibradora e lixadeira circular.

e) PEÇAS DE LIGAÇÃO LATERAIS: Duas peças no tamanho $24 \mathrm{~cm}$ de comprimento por $3 \mathrm{~cm}$ de altura e $2 \mathrm{~cm}$ de espessura. Estas duas peças também passam pelo mesmo processo descrito para as PEÇAS DE LIGAÇÃO FRENTE E VERSO.

f) PEÇA UNICA: A peça "única" é o ponto principal deste produto, pois é ela que o torna diferente, cada aparador fabricado tem as características de uma peça exclusiva. Essa peça é qualquer um tipo de resíduo de processamento mecânico ou outros provenientes de madeiras amazônicas seja de resíduos florestais ou de árvores naturalmente caídas dentro das medidas de $110 \mathrm{~cm}$ de comprimento por $28 \mathrm{~cm}$ largura com $2 \mathrm{~cm}$ de espessura que obedeça pelo menos um dos requisitos: apresentar broca, irregularidade do fuste, ser costaneira, apresentar desenho estrutural na madeira (exemplo de espécie que pode ser utilizada nesse caso: Angelim Rajado (Pithecellobium incuriale), cerne e alburno distintos. Após a seleção dos resíduos que contemple um dos requisitos descritos anteriormente, estes passaram por máquinas como serra circular, plaina desempenadeira, serra de fita para realizar cortes de dois por três centímetros para encaixe das pernas, plaina desengrossadeira (podendo não ser necessária se o resíduo apresentar broca), calibradora (podendo não ser necessária se o resíduo apresentar broca) e lixadeira circular.

g) VIDRO: o vidro é de cinco milímetros de espessura, com $110 \mathrm{~cm}$ de comprimento por $28 \mathrm{~cm}$ de largura.

Esta ordem de execução descrita anteriormente foi estabelecida após o processo de fabricação da alternativa proposta de aparador onde toda a parte estrutural é apta a ser inserida em linha de produção, sendo sua singularidade encontrada na denominada peça única. Os resíduos foram selecionados e processados para a obtenção das peças para a confecção do aparador. Para a "peça única" foi selecionada peça de angelim vermelho apresentando broca, a mesma passou por um processo de remoção de impurezas externas à madeira, foi processada nas máquinas da marcenaria e foi dimensionada conforme as medidas estabelecidas no projeto (FIGURA 05 e 06). As demais peças do aparador foram produzidas a partir de outros resíduos madeireiros de processamento mecânico. Os testes de utilização foram realizados bem como o refinamento do artefato, buscando a correção dos impasses não percebidos no modelo 3D. 


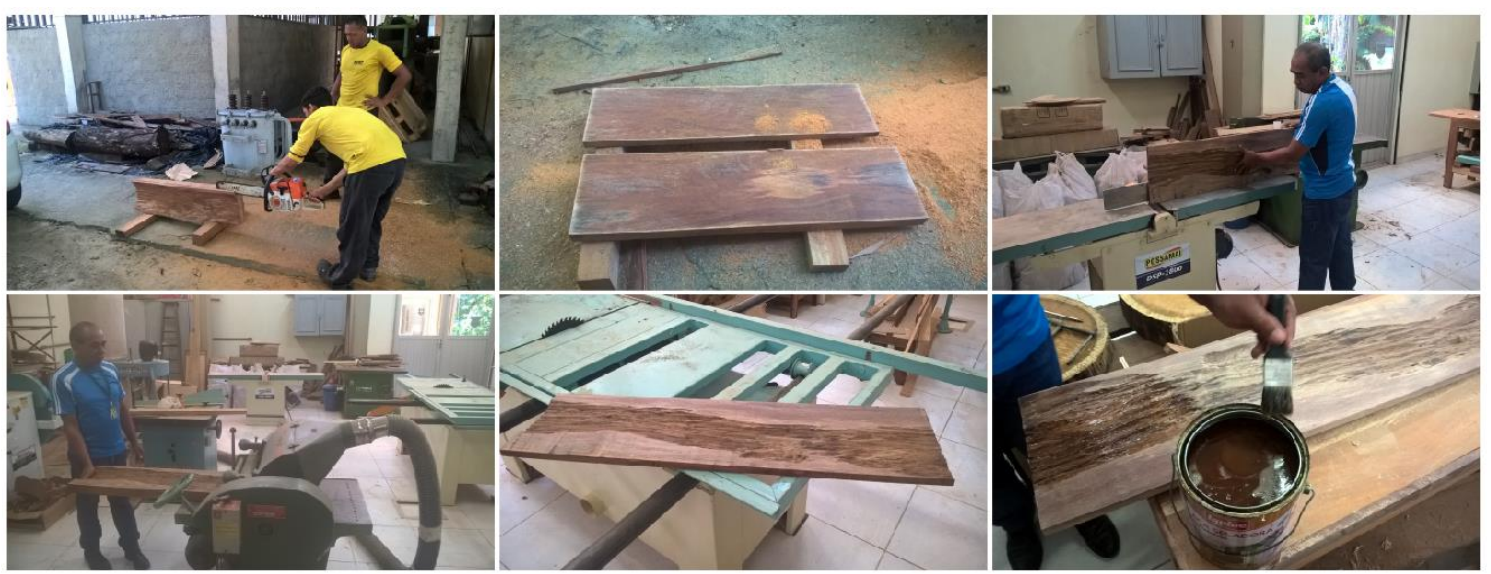

Figura 05. usinagem de peça de angelim vermelho. Fonte Própria, 2018.

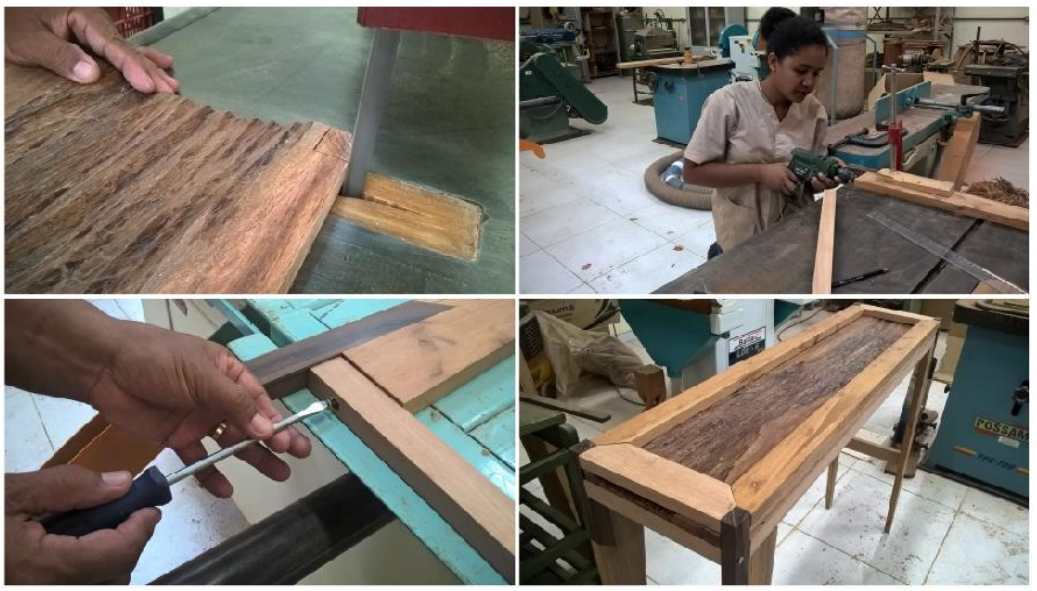

Figura 05. Montagem do artefato para verificação do dimensionamento e possíveis correções. Fonte Própria, 2018.

\subsubsection{Mesa de Centro Curumim}

Esta solução é aplicada ao uso de discos de madeira. A alternativa proposta de mesa de centro, utilizada como elemento decorativo em ambientes residenciais e comerciais sendo mais comum em salas de estar e de espera, foi desenvolvida objetivando que poucas peças fossem necessárias para sua composição, tanto que são apenas cinco. Sendo três pernas, um disco (conhecido popularmente como bolacha) de madeira, e um círculo de vidro. As peças são unidas por meio de parafusos. O material predominante é a madeira. Visto também que a peça de maior importância quanto a utilização nesse produto é o disco de madeira. A madeira utilizada na confecção da mesa de centro pode ser proveniente de resíduos de processamento mecânico, resíduos florestais e madeira de árvores naturalmente caídas. A alternativa foi desenvolvida a partir de desenhos esquemáticos, modelada em software CAD Solid Edge e posteriormente teve seu protótipo confeccionado para validação de uso da mesma.

Foi estabelecida uma sequência de execução das peças a partir do processo de produção do protótipo das mesmas. Primeiramente, para as peças que são de madeira, selecionou-se a madeira de acordo com o tamanho da peça a ser produzida. Abaixo segue uma descrição das peças que compõem a mesa e seus respectivos processos de fabricação: 
a) DISCO DE MADEIRA: O disco de madeira é obtido a partir do corte transversal no momento de desdobro da tora ou posteriormente. Para esta mesa utiliza-se disco com $6 \mathrm{~cm}$ de espessura, $75 \mathrm{~cm}$ de diâmetro no máximo (levando em consideração a densidade da madeira e o ambiente no qual a mesa será inserida) e $50 \mathrm{~cm}$ de diâmetro no mínimo, pois este é o tamanho máximo permitido para que uma árvore possa ser derrubada, já no caso de a madeira for proveniente de árvores naturalmente caídas este diâmetro pode ser ainda menor. Após selecionar o disco submeteu-se o mesmo a tratamentos manuais para a eliminação de sujeira e possíveis coleópteros que ainda estevam atacando a madeira. Fezse uso de ferramentas como formão, escova de aço, lixas de variados grãos e lixadeira circular manual para nivelar a peça. $O$ disco pode ser submetido a máquinas mais potentes se não apresentar broca e ou outro fator que venha a danificar a peça. Logo após este procedimento transferiu-se o desenho dos cortes de encaixe para face a ser escolhida do disco e então o corte pode ser realizado utilizando a máquina serra de fita. Para acabamento do disco pode ser utilizada lixa de variados grãos e material para acabamento conforme as características da madeira selecionada.

b) PERNAS: As pernas da mesa de centro são de fácil execução e utilizaram pouca madeira na produção. Com $35 \mathrm{~cm}$ de altura, $6 \mathrm{~cm}$ de largura e $2 \mathrm{~cm} \times 3 \mathrm{~cm}$ na base dependendo do diâmetro do disco. A madeira selecionada, dependendo do seu estado e tamanho, pode passar por máquinas como serra circular, plaina desempenadeira e plaina desengrossadeira. Após este processo transferiu-se para a madeira o desenho do corte que se desejou obter e então a peça foi submetida à máquina serra de fita, logo após à máquina calibradora e depois para a lixadeira circular.

c) VIDRO: o Vidro utilizado apresenta espessura de $5 \mathrm{~mm}$ e seu diâmetro varia de acordo com o diâmetro do disco de madeira a ser utilizado.

A peça selecionada para obtenção do disco de madeira, foi serrada e então processada. Para as peças estruturais (pernas) (FIGURA 06) foi utilizado resíduo de processamento mecânico da madeira Angelim rajado (espécie) (FIGURA 06). O protótipo foi finalizado e então realizada a verificação quanto a estabilidade dimensional, elementos de ligação entre peças, peso, facilidade de montagem e manuseio. Os testes realizados no protótipo físico foram condizentes com o visualizado na modelagem 3D, a confecção do protótipo seguiu o dimensionamento previsto a partir do mesmo.
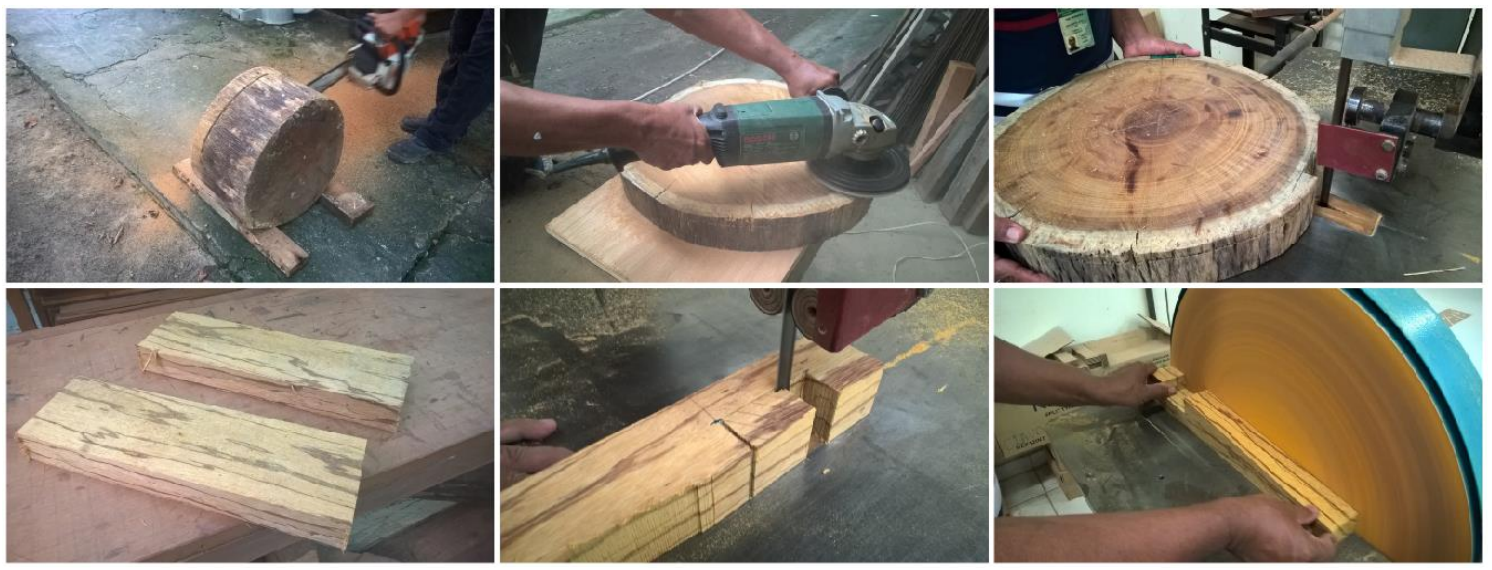

Figura 06. Processo de fabricação do protótipo da mesa curumim. Fonte Própria, 2018. 


\subsection{Detalhamento técnico}

\subsubsection{Aparador Rio}

Foi gerado detalhamento técnico para posterior reprodução do artefato utilizando os materiais citados como matéria prima (FIGURA 07). Visando repassar para terceiros a comercialização da peça.
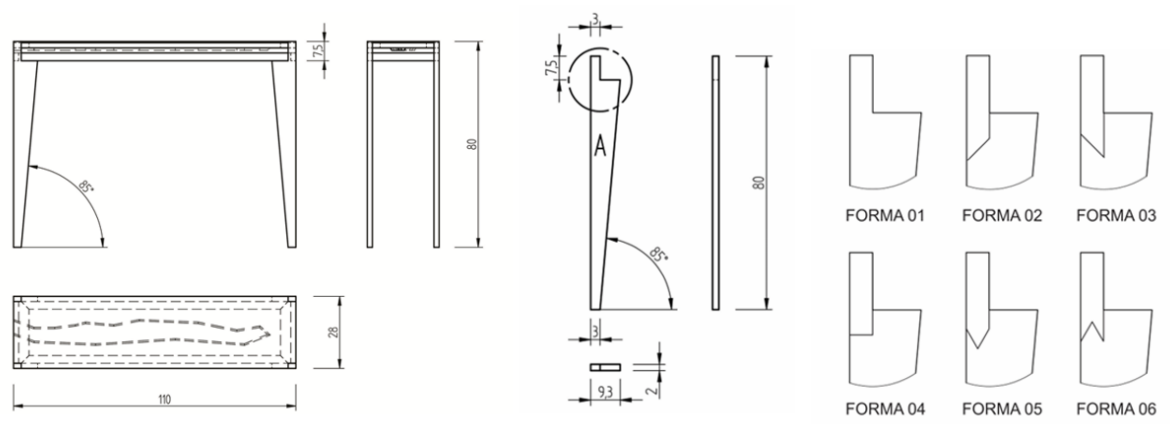

Figura 07. Vistas gerais e detalhes de modificação da forma. Fonte Própria, 2018.

\subsubsection{Mesa de Centro Curumim}

O detalhamento técnico da alternativa de mesa de centro também foi concluído (FIGURA 08). Como o material em questão é o disco de madeira o qual não apresenta uniformidade na peça, durante o processo de geração de alternativa foi estabelecido um método indicativo para corte do disco e montagem das peças, onde as mesmas são distribuídas com espaços de $120^{\circ}$ entre si de forma que é formado um triangulo equilátero visando a perpendicularidade da área de contato das peças de sustentação com o centro do disco (FIGURA 09).
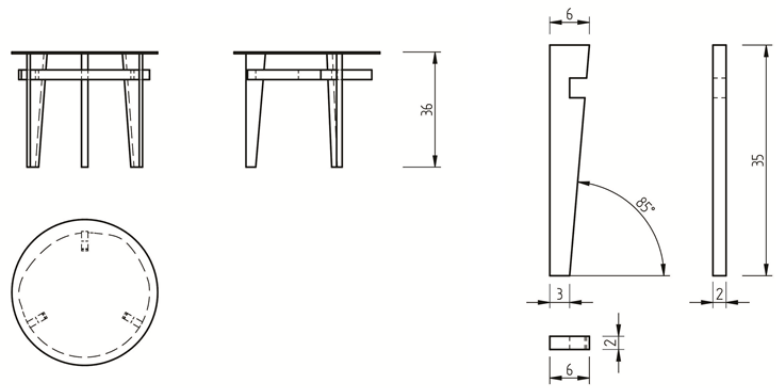

Figura 08. Vistas gerais. Fonte Própria, 2018.

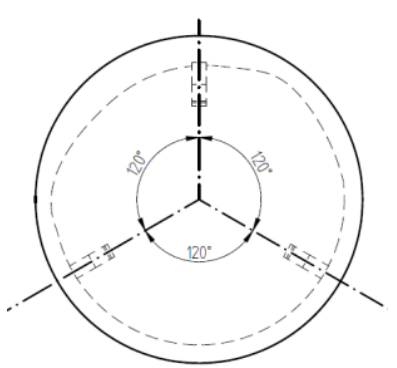

Figura 09. Indicação de montagem da peça. Fonte Própria, 2018. 


\section{Resultados}

Os objetivos aos quais se propôs a pesquisa foram alcançados com êxito uma vez que as alternativas propostas atenderam aos requisitos e parâmetros projetuais estabelecidos e fizeram uso de material colocado como centro da pesquisa. Os dois produtos tidos como resultado mostraram viabilidade quanto ao processo de fabricação e utilização da matéria prima.

A proposta de aparador apresenta facilidade de modificação em suas peças de sustentação (pernas) e, principalmente, o uso de resíduos totalmente descartados como peça principal que é a responsável por diferenciar um aparador de outro, tornando-o peça única, peça exclusiva para seu consumidor final (FIGURA 10). Toda a parte estrutural do aparador pode ser produzida em série, mas a peça única não, não por que essa é um dos diferenciais deste produto, a peça única apresenta particularidades diferentes das demais, por exemplo: uma peça brocada não é igual à outra que também não apresenta as mesmas características de uma peça que dispõe de cerne e alburno bem distintos entre si (FIGURA 11). O intuito com essa alternativa foi dar uma nova possibilidade de fim a resíduos florestais e de processamento mecânico. Visando aqueles que são impossibilitados de serem comercializados por conta de imperfeições e ou variações quanto ao padrão estabelecido para comercialização da madeira. A forma geométrica da alternativa contempla três principais vantagens: facilidade de produção e reprodução, utilização de poucas máquinas para a sua fabricação e reutilização de resíduos provenientes de processamento mecânico. E uma das principais vantagens é que o mesmo faz uso de resíduos que geralmente são descartados no meio ambiente ou são utilizados para a produção de energia através da queima, resíduos estes que apresentam brocas ou imperfeições, características que podem limitar o uso destes pela indústria da madeira. O presente produto apresenta formas simples, atrativas e funcionais facilmente reproduzíveis. Pode ser utilizado como elemento de decoração em ambientes residenciais e comerciais.
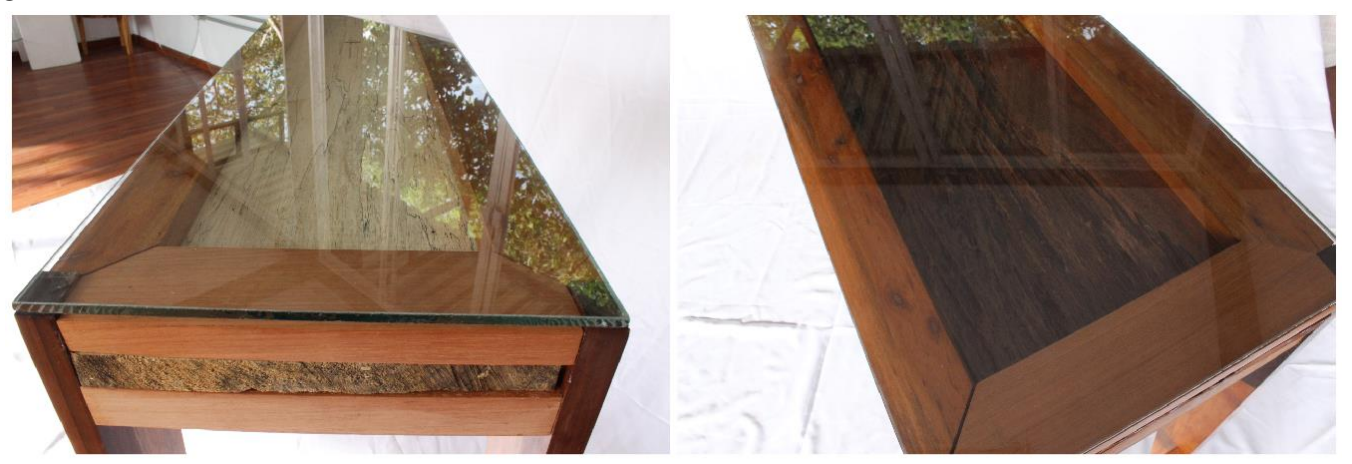

Figura 10. "peça única" a esquerda de Marupá e a direita de angelim vermelho. Fonte Própria, 2018.
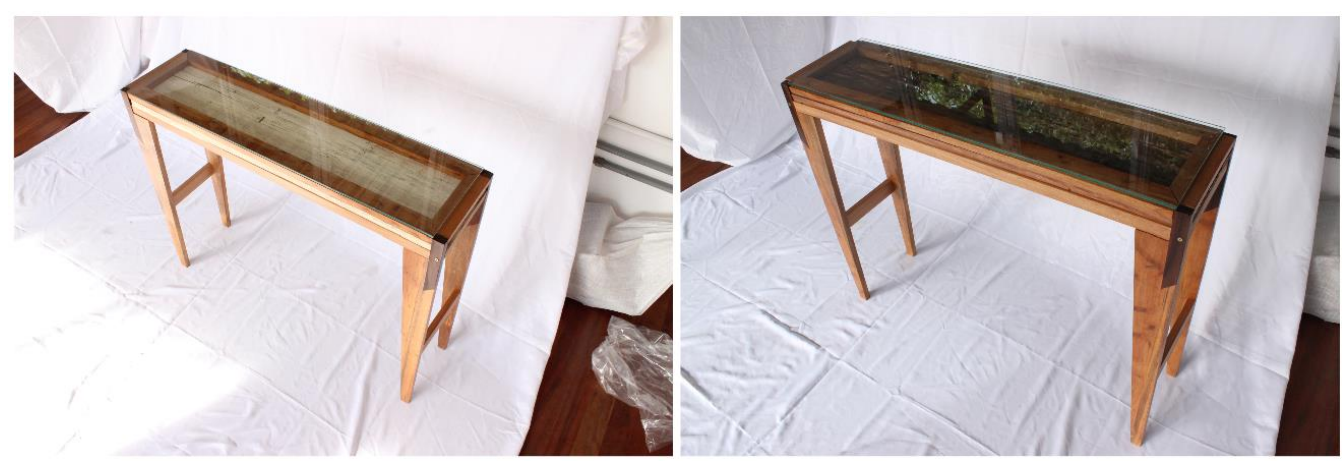

Figura 11. exemplo de possibilidade de troca da "peça única" na mesma estrutura. Fonte Própria, 2018. 
A alternativa de mesa de centro foi voltada para o uso de disco de madeira e traz como novidade a simplicidade que apresenta no processo de fabricação, a facilidade de montagem e desmontagem (FIGURA 12). Faz-se necessário poucas máquinas para a sua produção. E a peça de destaque que é o Disco de madeira é proveniente de resíduos geralmente descartados por não encontrarem espaço em meio a indústria da madeira. As formas geométricas das peças apresentam vantagens como pouca utilização de recursos humanos para sua concepção, facilidade de produção em série e fácil manuseio (FIGURA 13). Em visita a restaurantes regionais e até mesmo observando algumas moradias é possível encontrar similares da mesa curumim, mas a diferença encontrada é a questão do emprego do detalhamento técnico, uma vez que os similares observados foram feitos de forma totalmente artesanal sem preocupação com estabilidade dimensional, acabamento e elementos de ligação entre peças.

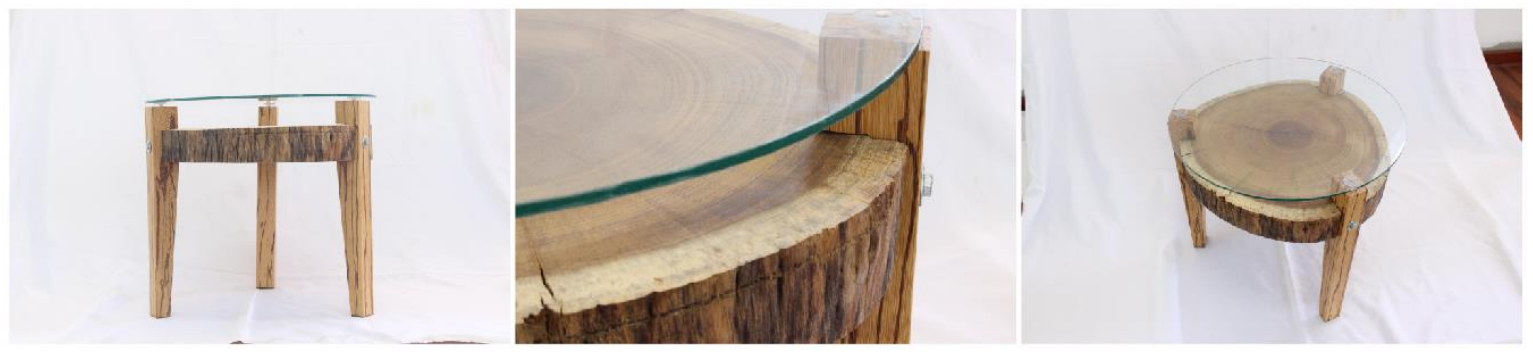

Figura 12. Mesa de Centro. Fonte Própria, 2018.

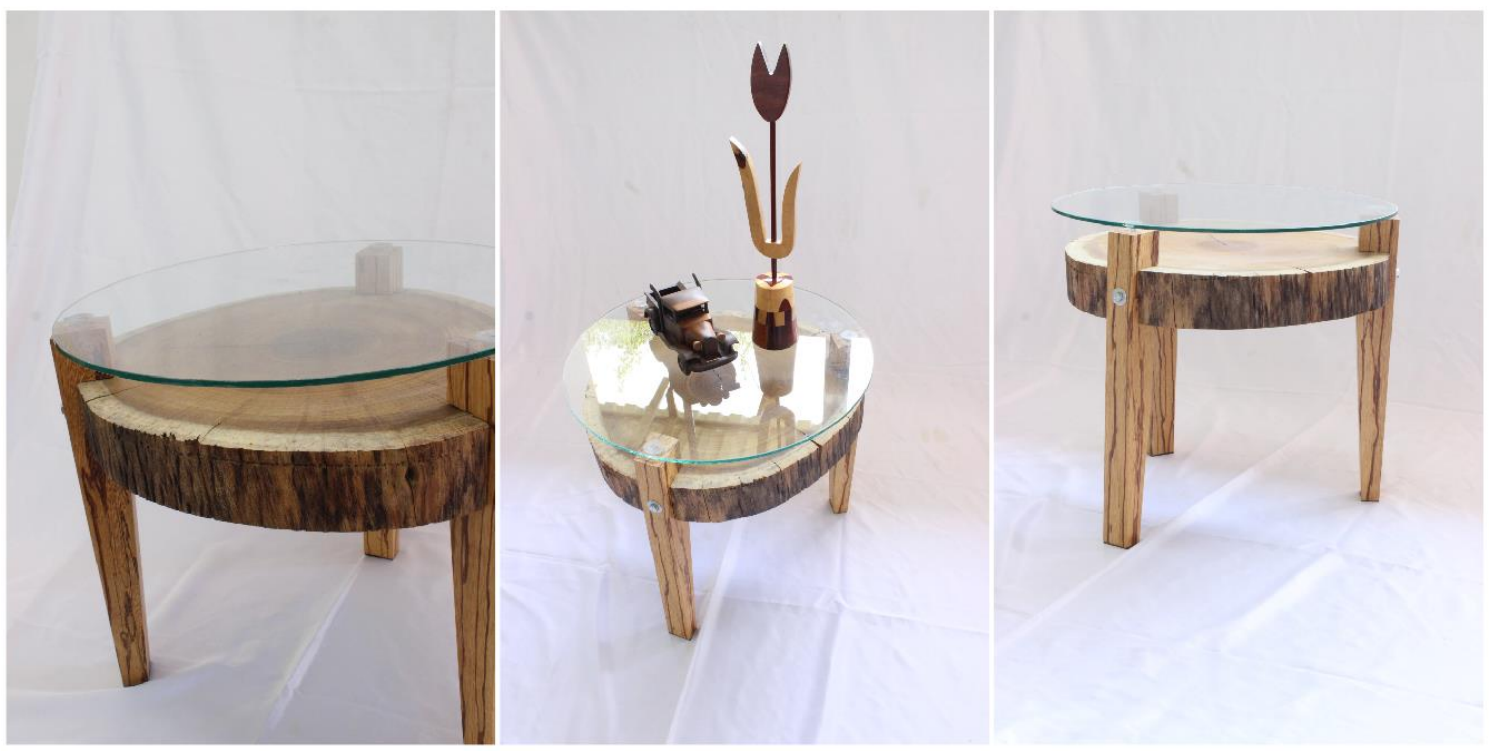

Figura 12. Mesa de Centro. Fonte Própria, 2018.

Comprovou-se por meio das duas alternativas aqui apresentadas que é possível utilizar resíduos de processamento mecânico e florestal mesmo que estes apresentem irregularidades em sua forma física, de forma que a produção possa ser realizada em longa escala acompanhada de detalhamento técnico das peças. A sequência de execução das peças mostrada na geração de alternativa, se seguida corretamente, tem como resultado produtos de qualidade capazes de serem repassados a terceiros para sua reprodução. 


\section{Conclusão}

Ao final da pesquisa os protótipos foram expostos a fim de serem avaliados para identificação de viabilidade técnica e econômica. A conclusão que se teve foi que os produtos confeccionados apresentam viabilidade comercial e que são passíveis de serem produzidos em larga escala a partir do detalhamento técnico apresentado. Além de se comportarem como uma nova destinação aos resíduos madeireiros abordados pela pesquisa.

Com a correta aplicação do design de produto ao problema identificado, que se configura como o descarte de resíduos madeireiros florestais e provenientes de processamento mecânico e de arvores naturalmente caídas, observou-se por meio dos resultados que se pode chegar a soluções projetuais plausíveis, a partir do momento em que as mesmas trazem uma carga de detalhamento técnico como demonstrado na metodologia além do alto valor agregado a matériaprima. O ponto crucial tido como resultado conclusivo dessa pesquisa foi o fato de que houve uma segunda alternativa de uso para tais resíduos, antes incinerados e tidos como estorvo, agora, a partir das propostas apresentadas, composição de produtos com alto valor agregado.

Há uma grande discussão quanto a correta aplicação do manejo florestal na exploração madeireira amazônica, e a tecnologia da madeira é tida como uma das soluções, e o Design se situa nesse ponto. Essa relação com a tecnologia da madeira, trazendo à tona as possibilidades de uso de tais resíduos e até mesmo da madeira certificada beneficiada para comercialização.

Por fim, a partir dos resultados alcançados verificou-se não só a importância de solucionar problemas relacionados ao descarte de resíduos madeireiros, mas a integração de profissionais de Design, com a responsabilidade de não apenas empregar apelo estético, mas toda a técnica necessária para que os produtos atinjam os objetivos, os quais os principais são tornar viável tanto economicamente quanto tecnicamente as alternativas desenvolvidas. 


\section{Referências}

BARBOSA FILHO, A.N. 2009. Projeto e desenvolvimento de produtos. Atlas, São Paulo, 182p.

DIAS, R. S. 2011. Aproveitamento de toras ocas da Mezilaurus itauba para confecção de artefatos de madeira, 97p. Dissertação de mestrado, UFAM, PPGCIFA.

VENZKE, C.N. 2002. O Ecodesign no setor moveleiro do Rio Grande do Sul. REAd - Edição especial 30 Vol. Disponível em: < http://www.lume.ufrgs.br/handle/10183/19604?locale=pt_BR>Acesso em 12/11/2015.

LOPES, C. S. D. 2009. Desenho de pequenos objetos de madeira com resíduo da indústria de processamento mecânico da madeira. Disponível em: < http://www3.sp.senac.br/hotsites/blogs/InterfacEHS/wpcontent/uploads/2013/08/7_ARTIGO_vol4n3.pdf > Acesso em 17/02/2018

SILVA, G. I. R.C. 2017. Análise da viabilidade de produção de madeira-plástica utilizando poliestireno (ps) e madeiras da amazônia. Disponível em: < https://tede.ufam.edu.br/handle/tede/5874> Acesso em: 17/02/2018

VIEIRA, R. S. 2006. Pequenos objetos de madeira de eucalipto: possibilidade de aproveitamento de resíduo. $\quad$ Disponível em:< http://repositorio.ufla.br/bitstream/1/3926/1/DISSERTA\%C3\%87\%C3\%830_Pequenos\%20objetos \%20de\%20madeira\%20de\%20eucalipto\%20possibilidade\%20de\%20aproveitamento\%20de\%20res \%C3\%ADduo.pdf> Acesso em 17/02/2018 